\title{
Integration of ICT-learning Environments: A paradigm Shift from Traditional Teaching Pattern
}

\author{
Shakeel Ahmad Siddiqui ${ }^{1}$, M. Afshar Alam ${ }^{1}$, Javed Azmi ${ }^{1}$, Md. Omair Ahmad ${ }^{1}$, Refia Wiquar ${ }^{1}$, Asfia Aziz ${ }^{1}$ \\ \{siddiquishakeelahmad@gmail.com $\left.{ }^{1}\right\}$ \\ ${ }^{1}$ Department of Computer Science and Engineering, Jamia Hamdard, New Delhi
}

\begin{abstract}
This research paper will holistically analyze the impact and benefits of ICT applications in educational institution. It will also explore the traditional methods of teaching and its limitations. It will make comparative study between ICT adoption and traditional methods of study and it will deeply explore and develop the integration mechanism vis-a-vis information and communication technologies (ICT) with conventional teaching methodology. It will also highlight the instructor perception and attitude towards ICT while using ICT in the classroom. It will analyze how rampantly the ICT has spread its tentacle in almost all educational establishments. This research paper will thoroughly explain the opinions of students regarding ICT as well as the negative outcomes of traditional teaching methodology.
\end{abstract}

Keywords: Online learning, ICT products, ICT services, Electronic Resources, Traditional teaching, blackboard, attitudes.

\section{Introduction}

Information and communication technology (ICT) has a big presence that enormously contributed and greatly catapulted the whole gamut of the current scenario of computing world. ICT has widely grabbed every field. The application of ICT in the previous past two three decades, has been mammoth and it is still growing extremely fast. Today, whatever, the use of ICT application, we are observing, is quite different from the past. [1]The impediment in the way of efficient use of ICT in academics were the complete absence of funding facility and motivation towards the implantation of ICT in the Universities and colleges. These were some of the glaring reasons behind the slow implementation ICT. But currently, the favorable environment emerged that greatly strengthened the quick moves with regard to adopting ICT into classrooms and in other learning settings. The implementation of ICT rapidly provided the platform for efficient program delivery and the fulfilment of customized educational programs. [2]The rapid growth of Information and communication Technology (ICT) has reshaped and challenged the stereotyped traditional methods of teaching, and really that changed the whole landscape globally. Traditional teaching felt to be lethargic and less competent than that of ICT. Now most of the teachers prefer to teach through ICT methods. [3] And it is believed that modern ICT devices are more comfortable than tradition ways of teaching delivery adopted in the recent past. [4] 
Now a days, at most of the academic's settings, ICT presence is widely available, and most of the students prefer to learn through ICT devices, and very swiftly the old traditional black board teaching methodology is about to be ceased to exist. As the stereotyping in direct lecture methods by the instructors seems to be rejected and dejected kinds of things now. It is observed that the traditional teaching is exploitative in nature and is not suitable for the ongoing academic environment. One may say that this ICT has the abilities and capabilities to reshape the whole scenario of academic settings. And undoubtedly to make ICT more viable and suitable, all sorts of snags must have to be eliminated forthwith.

\section{The Impact of ICT and Traditional Teaching Methods}

Students remain fully dependent on their teachers on study related matter. Such issues before them creates a situation of boredom and such traits suppress the creativity in them and also dampened the future growth of their personality. In traditional teaching, there is chance of favoritism with students.[5] This kind of things may be advantageous for students as the training and lecture delivery are directly interacted between teachers and students. But its few disadvantage is that there might not be the equal attention by the teachers towards all the attending students. Traditional teaching methods are comparatively very expensive as well.[6] The contemporary ICT support system is very much dynamic as it supports all urgently needed requirements.[7] From a long time back, it was felt to be required a very dynamic ICT support system, but due to certain limited resources, applications of ICT were not adequately implemented in the academics. However, all those impediments in its ways have gradually been removed and it is rampantly being used in almost all sorts of academics.

\subsection{The Potential Benefits of ICT}

ICT has transformed the whole set of teaching methods and that has brought a considerable benefit in supporting systems. The learning with the support of ICT has awarded them with what they need, why they need and how can they retrieve data Vis-a- Vis their requirements.[8] It is an active learning support system by directly logging with the websites. That is why it can be termed as an independent system without dependency on teachers. By using different blogs, for example, can make anyone updated with the recent progress or introduction of information or issues in educational sector or in other sectors.

\subsection{Attitude of Students Regarding ICT Adoption in Academics}

The term "attitude" means the general assessment or feeling of favorable or unfavorable disposal of a person towards ICT or specific activities using ICT[9]. This term, "attitude" refers to the general assessment or favorable or unfavorable feeling of a person regarding anything. Here, in this study, the attitudes were observed and enumerated by putting questionnaire directly to the students. 


\section{Objective of the Study}

The following tools were applied for the collection of data:

A questionnaire based on the student's association/relations with ICT were served among the students. And with the support of that questionnaire, it was tried to be estimated that what and how they use ICT in the classrooms. The questionnaire also investigated to know the attitude and opinions of the student regarding ICT applications in the classrooms. Students responded through questionnaire for their attitudes towards ICT, after the completion of semester - end examination

1. To analyze and find out the aims of using ICT devices or products.

2. To analyze and find out the awareness and knowledge of various ICT products.

3. To analyze and find out how many times they use ICT products.

4. To analyze and identify the problems before students while using ICT products and services.

5. To provide suggestions and directions as well as conclusion of the study.

\section{RESEARCH METHODOLOGY}

In this study, a full- fledged questionnaire were used for the collection of data. The questionnaire was designed with multiple options and put before the UG/PG students of Jamia Hamdard. During that process, the students were also asked to give their recommendation vis-à-vis ICT products and services and were also sought opinions regarding traditional teaching methodologies.300 set of questionnaires were distributed among the randomly chosen students from different departments. Altogether 225 filled-up feedbacks/opinions obtained. On getting that feedback/opinions, analysis was made for this study.

\section{SCOPE AND LIMITATIONS OF THE STUDY}

The scope of the study is widespread, and it will open a new learning, and new innovative ideas among the students. It will greatly enhance the capabilities and abilities that how the proper use of ICT can be made in a right direction and how it will pave the ways for next Gen. During the study, some of the bottlenecks in its utilizations were also enumerated. This study remained confined among the UG/PG students of Jamia Hamdard, New Delhi.

\section{ANALYSIS AND INTERPRETATION}

Analysis and interpretations were made based on different data collected through questionnaire. Also, during teaching slots, recording of students' abilities and their inclination towards ICT applications were meticulously summarized. Keeping in view of the objectives of the present 
research work, the collected data were checked and analyzed with the help of statistical methods/tools and presented in the following figures given below:

\subsection{Attitude of UG \& PG Students on ICT based teaching:}

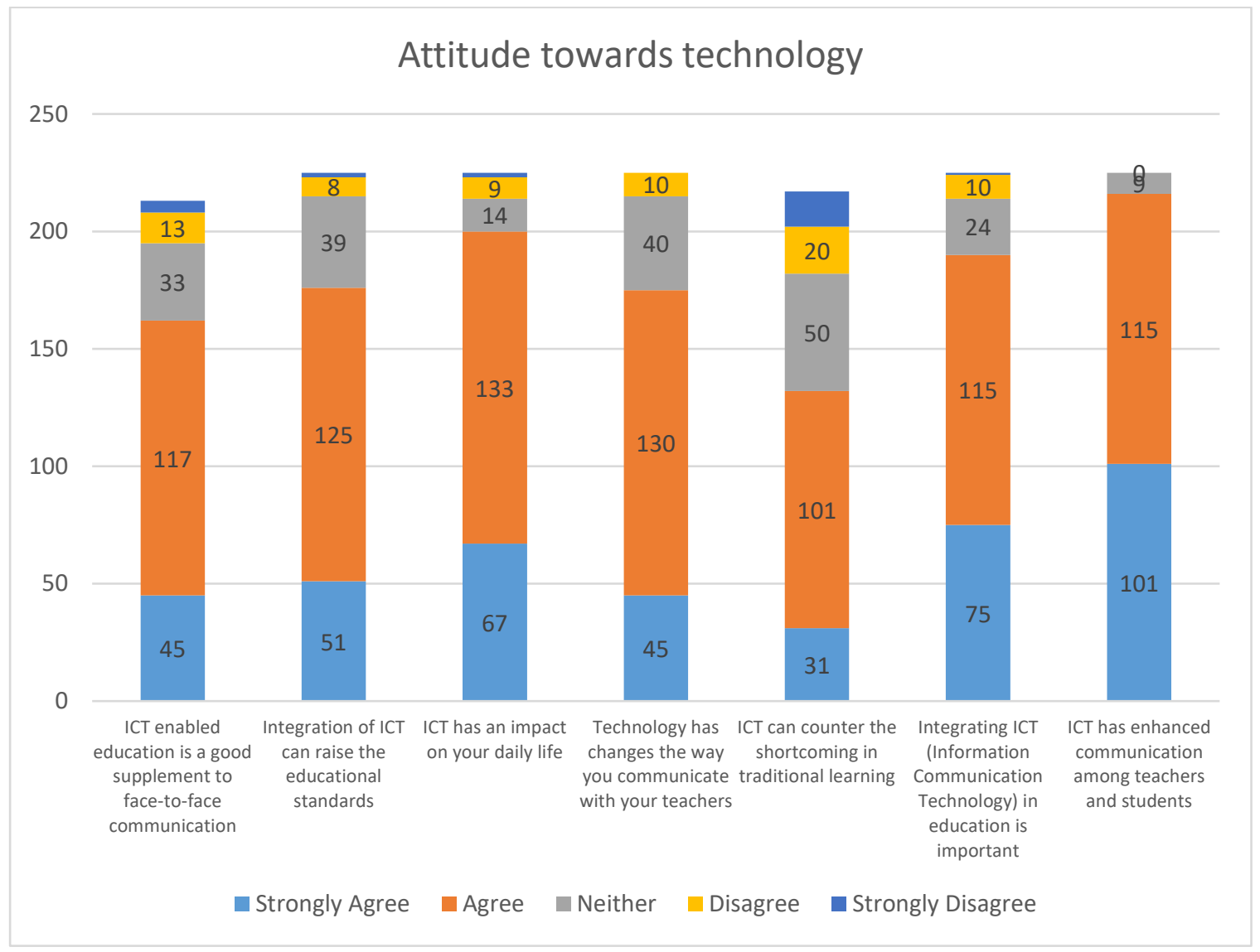

Fig. 1. 20\% students strongly agreed,52\% students agreed for ICT enabled education as good supplements. 22\% students replied as strongly agreed. 55\% replied as agreed for integrated ICT methods of teaching. 


\subsection{Access to Technology:}

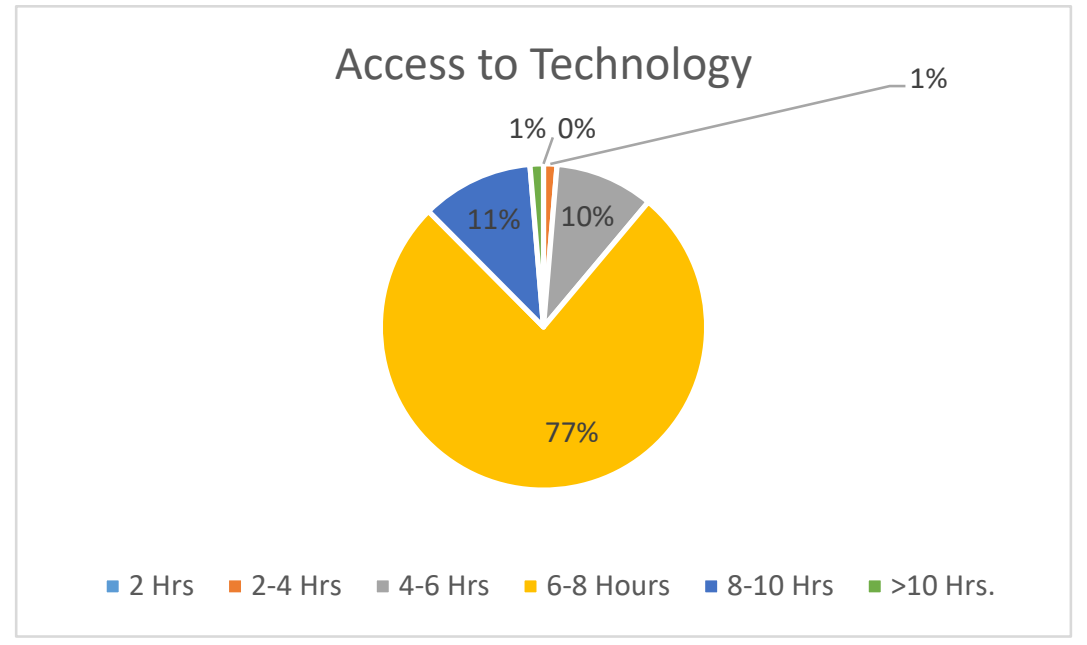

Fig. 2. 77\% students are using 6-8 hour used ICT enabled services in a week. However, $11 \%$ used between 8-10 hours in a week, though 10\%, 4-6 hour spent using ICT facility available with the University.

\subsection{ICT at Jamia Hamdard}

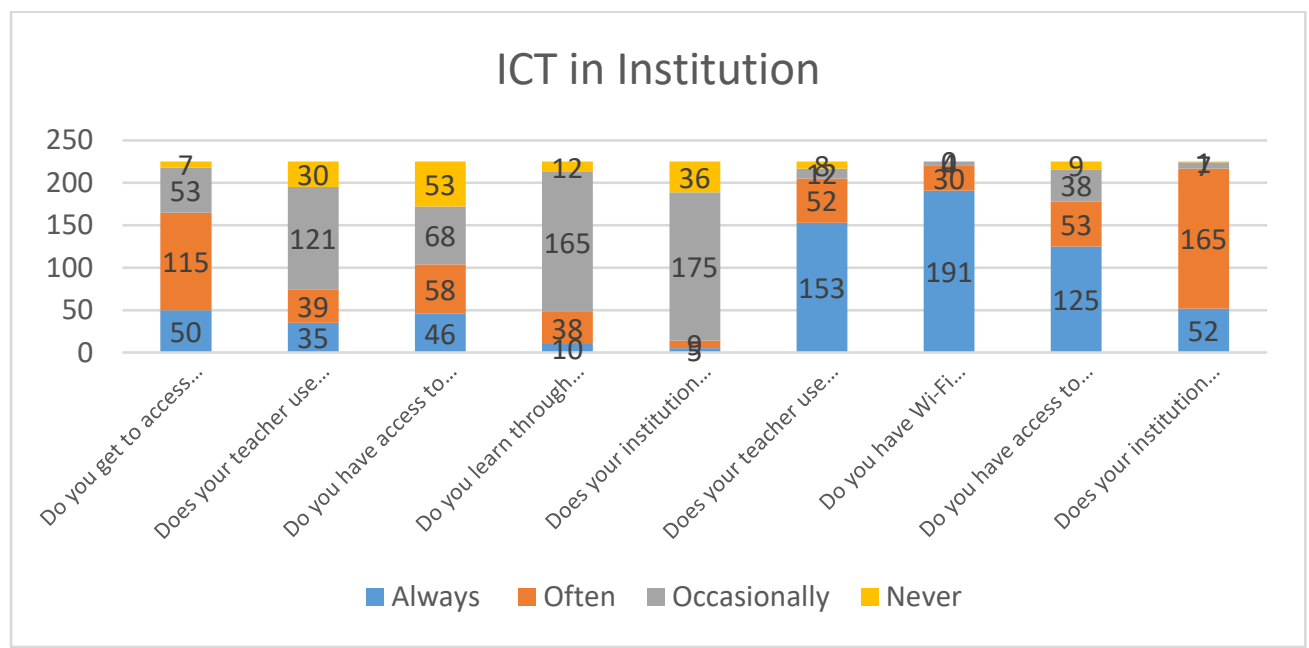

Fig. 3. According to this figure, most of the students replied as "Always" using ICT enabled Services after Lab hour, teachers' uses power point presentation for teaching, access to computers in institution. 


\subsection{Devices used by the Students}

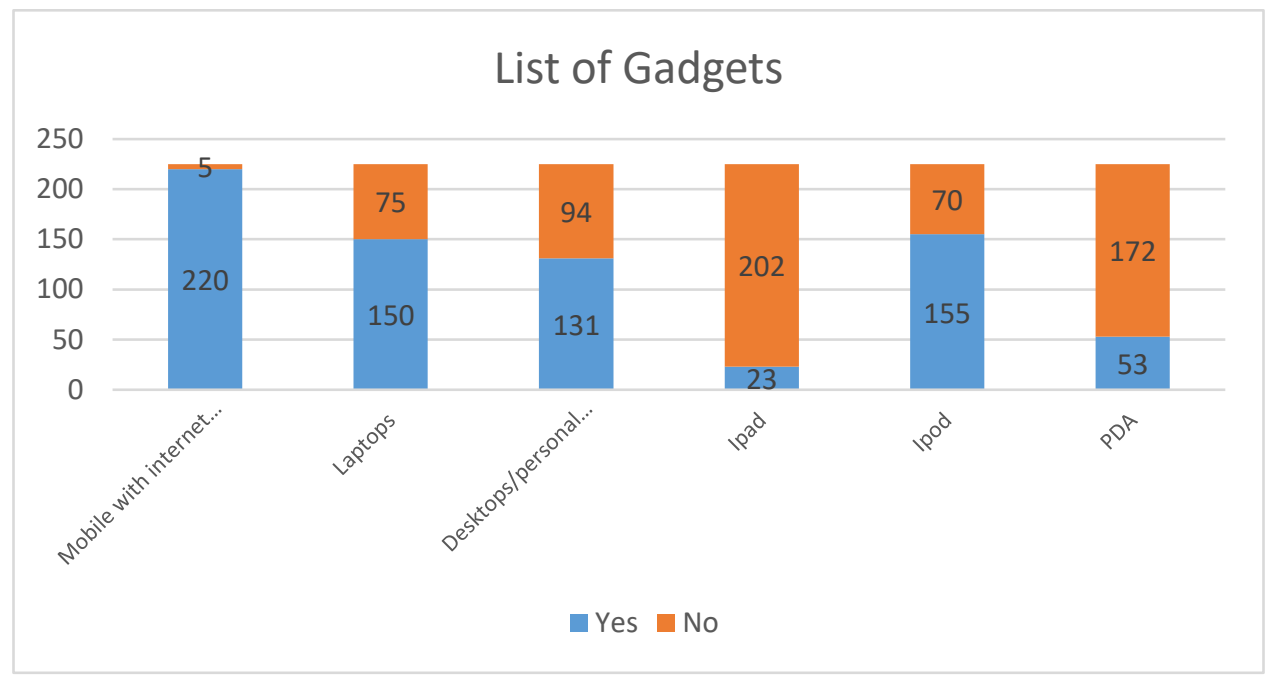

Fig. 4. Most of the students has carried Mobile with internet facility. Having Laptop, and iPod among them iPad and PDA were used very few.

\subsection{Knowledge of ICT}

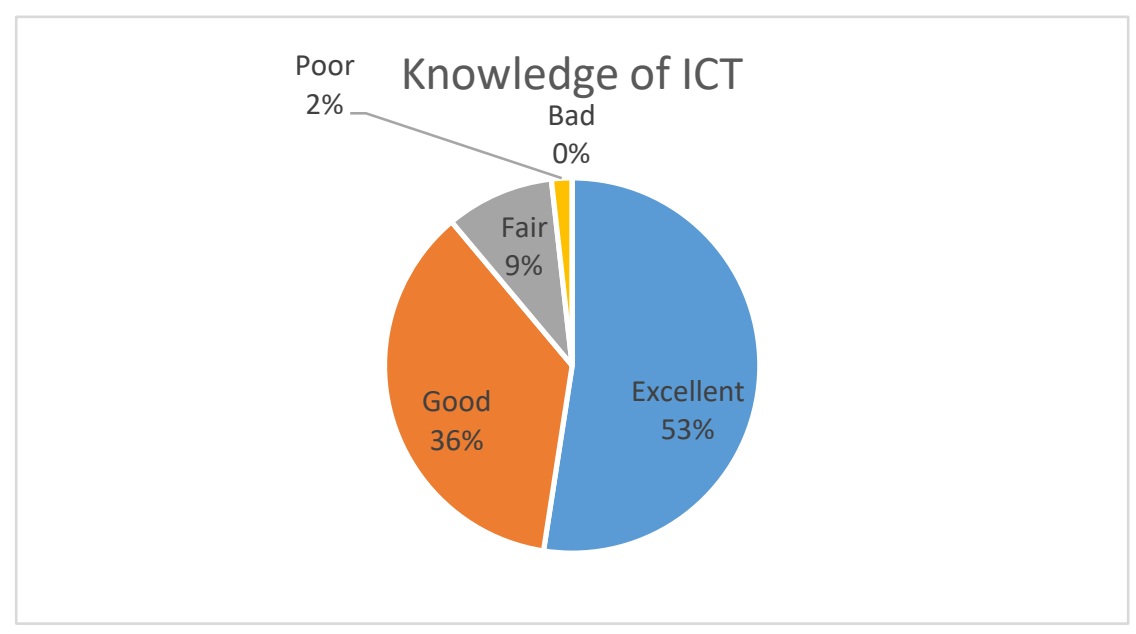

Fig. 5. $53 \%$ students found to be excellent in ICT applications whereas $36 \%$ are good. 


\subsection{Listing the activities performing with the Computer}

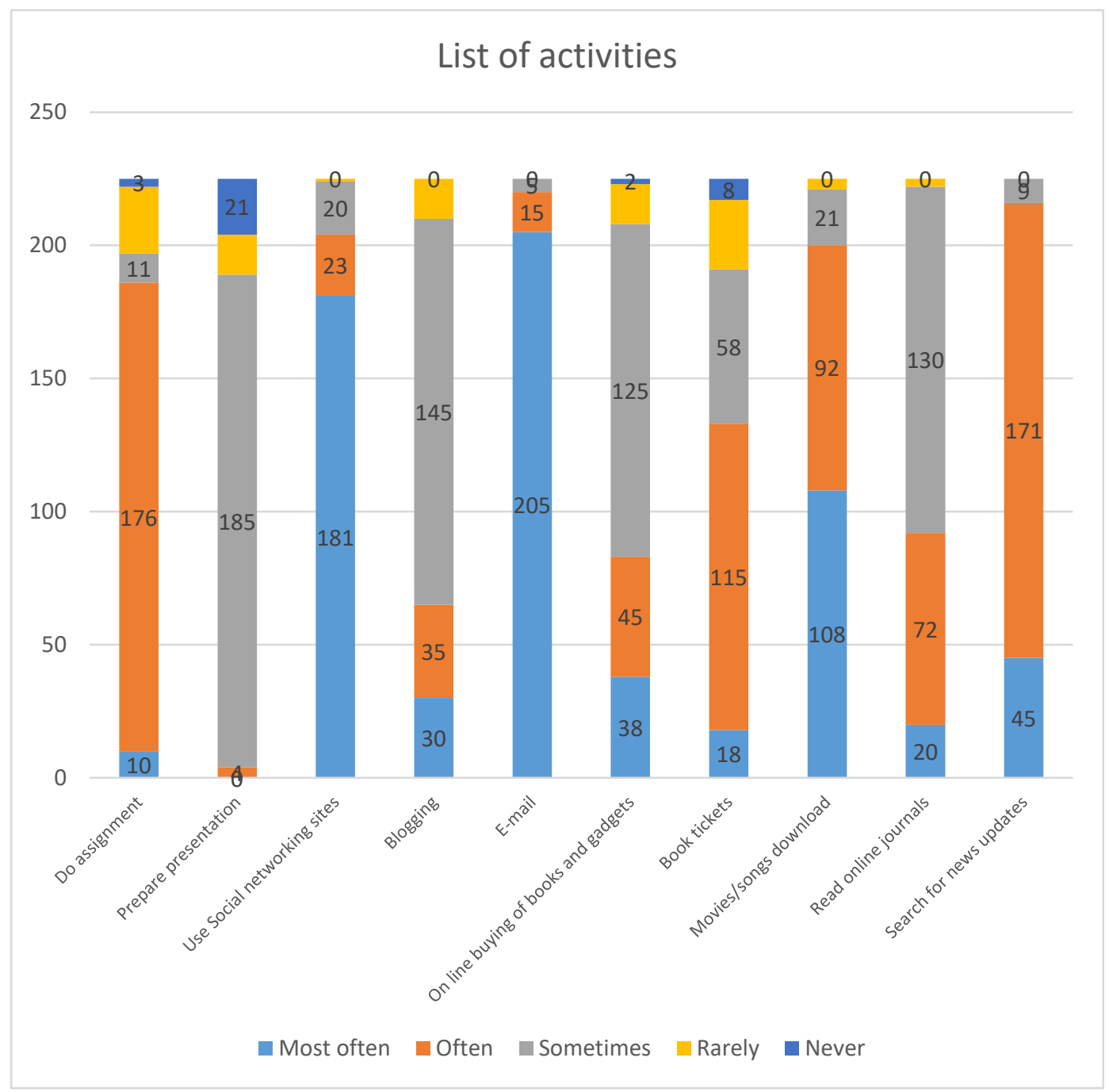

Fig. 6. Most of the student found to be engaged with email access, social networking sites, movie and songs downloading. 


\subsection{Behavior changes pertaining to ICT}

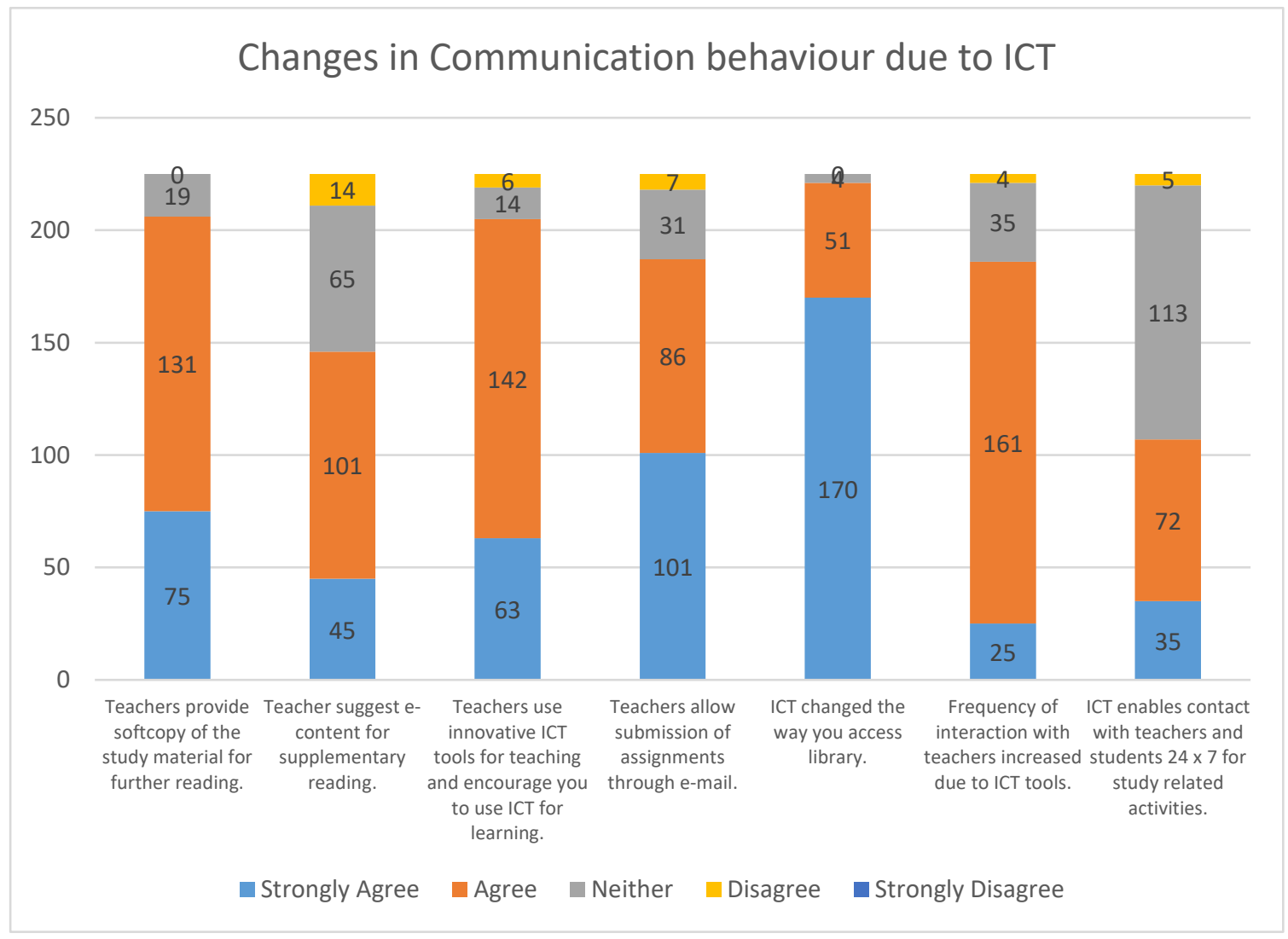

Fig. 7. Strongly Agreed- $75 \%$ students have access Library resources, $45 \%$ students has submitted there through email, Agree- $71 \%$ students replied as Frequency of interaction with teachers increased due to ICT tools, $63 \%$ teachers used innovative ICT tools for teaching and 58\% students replied as Teachers provided study material. 


\subsection{Impact of ICT on Learning Process among the students:}

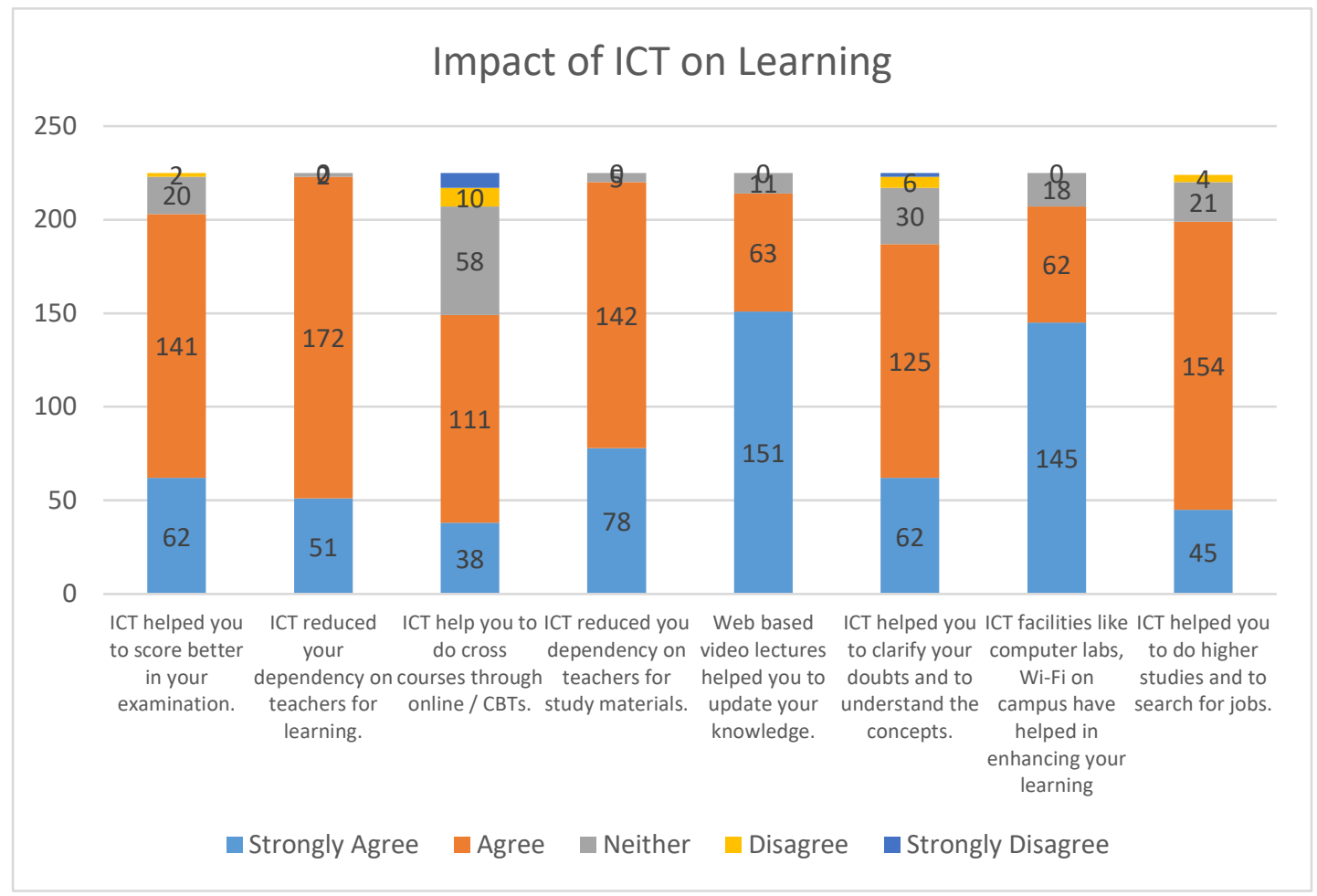

Fig. 8. Strongly Agreed-67\% students agreed web-based lectures updates their knowledge, 64\% students has replied vis -a-vis ICT facilities of learning like Computer lab and Wi-Fi, Agree- 76\% students replied as ICT reduced dependencies upon teachers., 68\% students agreed regarding, ICT helped for higher studies and search for job and $63 \%$ students replied as reduced dependency on teachers.

\section{Conclusions}

From all available data and analysis, it proved that the role of ICT in education is considerably positive and benefitting mechanism for teaching in educational institutions. It has greatly impacted the whole teaching methods. The paradigm shift in teaching delivery system from the blackboard system has really revolutionized the whole pattern of teaching delivery system. It proved to be a very dynamic catalytic agent among many educational practices. Extrapolating current activities and practices, the continued use and development of ICTs within education will have a strong impact on: 
1. What is learned.

2. How it is learned.

3. When and where learning takes place.

4. Who is learning and who is teaching?

Implementing ICT in schools/educational institutions has many advantages. Each educational set up has its own drawbacks. Generally, the difficulties can be classified into different kinds of barriers. Those may be technological barriers, teacher's inability to cope up with it, refusal by students' and poor schools' infrastructure 'and non- availability of technological system. Based on abovementioned data, it shows that students take keen interest to adopt ICT in education, and teachers also diverted its attention towards ICT enabled mechanism and shifted from the stereotype mechanism that used to be adopted in earlier days. The research results validate the educational decision of using ICT. In future, this work could be continued: to compare with Traditional teaching methodology.

\section{REFRENCES}

[1] B. F. Klimov, "ICT Versus Traditional Approaches to Teaching," Procedia - Soc. Behav. Sci., 2012, doi: 10.1016/j.sbspro.2012.06.638.

[2] L. Webb, J. Clough, D. O'Reilly, D. Wilmott, and G. Witham, "The utility and impact of information communication technology (ICT) for pre-registration nurse education: A narrative synthesis systematic review," Nurse Education Today. 2017, doi: 10.1016/j.nedt.2016.10.007.

[3] G. Schwerdt and A. C. Wuppermann, "Is traditional teaching really all that bad? A within-student between-subject approach," Econ. Educ. Rev., 2011, doi: 10.1016/j.econedurev.2010.11.005.

[4] H. D. Hermawan, N. Deswila, and D. N. Yunita, "Implementation of ICT in Education in Indonesia during 2004-2017,” 2018, doi: 10.1109/ISET.2018.00032.

[5] L. R. Kearns, "The experience of teaching online and its impact on faculty innovation across delivery methods," Internet High. Educ., 2016, doi: 10.1016/j.iheduc.2016.06.005.

[6] J. Sappey Dr and S. Relf, "Digital Technology Education and its Impact on Traditional Academic Roles and Practice," J. Univ. Teach. Learn. Pract., 2010.

[7] D. Alt, "Science teachers' conceptions of teaching and learning, ICT efficacy, ICT professional development and ICT practices enacted in their classrooms," Teach. Teach. Educ., 2018, doi: 10.1016/j.tate.2018.03.020.

[8] F. E. Benmarrakchi, J. El Kafi, A. Elhore, and S. Haie, "Exploring the use of the ICT in supporting dyslexic students' preferred learning styles: A preliminary evaluation," Educ. Inf. Technol., 2017, doi: 10.1007/s10639-016-9551-4.

[9] P. Zhang, S. N. Aikman, and H. Sun, "Two types of attitudes in ICT acceptance and use," Int. J. Hum. Comput. Interact., 2008, doi: 10.1080/10447310802335482. 